Article

\title{
Improving Oil Recovery of the Heterogeneous Low Permeability Reservoirs by Combination of Polymer Hydrolysis Polyacrylamide and Two Highly Biosurfactant-Producing Bacteria
}

\author{
Shuwen Xue ${ }^{1} \mathbb{D}$, Yanhong Zhao ${ }^{2}$, Chunling Zhou ${ }^{2}$, Guangming Zhang ${ }^{3}$, Fulin Chen ${ }^{1,3, *}$ and Shiwei Wang ${ }^{1,3,4, * \mathbb{D}}$ \\ 1 Research Center for Oilfield Microbial Engineering, the College of Life Sciences, Northwest University, \\ Xi'an 710069, China; xuesw@nwu.edu.cn \\ 2 Research Institute of Oilfield Chemistry, Xi'an Changqing Chemical Group Co., Ltd., Xi'an 710018, China; \\ zhaoyanh0_cq@petrochina.com.cn (Y.Z.); zhouchunl_cq@petrochina.com.cn (C.Z.) \\ 3 Key Laboratory of Resources Biology and Biotechnology in Western China, Ministry of Education, the College \\ of Life Sciences, Northwest University, Xi'an 710069, China; zhangguangming@stumail.nwu.edu.cn \\ 4 Provincial Key Laboratory of Biotechnology of Shaanxi Province, the College of Life Sciences, \\ Northwest University, Xi'an 710069, China \\ * Correspondence: chenfl@nwu.edu.cn (F.C.); wangsw@nwu.edu.cn (S.W.)
}

Citation: Xue, S.; Zhao, Y.; Zhou, C.; Zhang, G.; Chen, F.; Wang, S. Improving Oil Recovery of the Heterogeneous Low Permeability Reservoirs by Combination of Polymer Hydrolysis Polyacrylamide and Two Highly BiosurfactantProducing Bacteria. Sustainability 2022, 14, 423. https://doi.org/ $10.3390 /$ su14010423

Academic Editor: Anastasia V. Penkova

Received: 25 November 2021 Accepted: 27 December 2021 Published: 31 December 2021

Publisher's Note: MDPI stays neutral with regard to jurisdictional claims in published maps and institutional affiliations.

Copyright: (c) 2021 by the authors Licensee MDPI, Basel, Switzerland. This article is an open access article distributed under the terms and conditions of the Creative Commons Attribution (CC BY) license (https:// creativecommons.org/licenses/by/ $4.0 /)$.

\begin{abstract}
Polymer hydrolysis polyacrylamide and microbes have been used to enhance oil recovery in many oil reservoirs. However, the application of this two-method combination was less investigated, especially in low permeability reservoirs. In this work, two bacteria, a rhamnolipid-producing Pseudomonas aeruginosa 8D and a lipopeptide-producing Bacillus subtilis S4, were used together with hydrolysis poly-acrylamide in a low permeability heterogeneous core physical model. The results showed that when the two bacterial fermentation liquids were used at a ratio by volumeof 1:3 (v:v), the mixture showed the optimal physicochemical properties for oil-displacement. In addition, the mixture was stable under the conditions of various temperature $\left(20-70{ }^{\circ} \mathrm{C}\right)$ and salinity $(0-22 \%)$. When the polymer and bacteria were mixed together, it had no significant effects in the viscosity of polymer hydrolysis polyacrylamide and the viability of bacteria. The core oil-displacement test displayed that polymer hydrolysis polyacrylamide addition followed by the bacterial mixture injection could significantly enhance oil recovery. The recovery rate was increased by $15.01 \%$ and $10.03 \%$, respectively, compared with the sole polymer hydrolysis polyacrylamide flooding and microbial flooding. Taken together, these results suggest that the strategy of polymer hydrolysis poly-acrylamide addition followed by microbial flooding is beneficial for improving oil recovery in heterogeneous low permeability reservoirs.
\end{abstract}

Keywords: low permeability reservoirs; polymer flooding; microbial flooding; compatibility; core oil-displacement

\section{Introduction}

Enhancing oil recovery (EOR) is one main concern of oil companies due to the extensive competition in petroleum industry and the huge demand on resources [1]. According to a report from U.S. Energy Agency, the world average oil recovery rate is $20 \%$ to $30 \%$, and the $70-80 \%$ remaining oil is still present in reservoirs after conventional recovery [2,3]. Low permeability oil resources are rich in the worldwide [4,5], and they account for $76 \%$ of the total remaining oil resources in China [5]. However, due to the complex structure and obvious fracture, the low permeability oilfields are difficult to be developed or have low recovery by conventional EOR technology, such as chemical flooding, gas injection, and thermal recovery [6-8].

Polymer flooding, a popular tertiary EOR method, has been tested in more than 200 fields or blocks around the world $[9,10]$, and it was reported to be able to recover 
the remaining oil from reservoirs up to $30 \%$ of the original oil in place. In general, it is considered that polymer flooding can improve water-oil fluidity ratio, plug high permeable zones, adjust water injection profile, and expand sweep volume and efficiency. Due to the characteristics of low porosity, low permeability, complex distribution of fractures, and large pore channels in low permeability oilfields, polymer is often used to plug micro-fractures at the far end of injection wells for deep profiles. China has become the main application area of polymer flooding in low permeability reservoirs, such as in the Daqing and Changqing Oilfields [11,12]. In conventional polymer flooding, hydrolyzed polyacrylamide (HPAM)-based gel systems and xanthan have been widely used [13-15], and some other modified polymers have also been studied, such as temperature and salt resistant monomer polymer, hydrophobic associating polymer, cross-linked polymer, and comb polymer $[16,17]$. However, for low permeability heterogeneous reservoirs, the oil recovery is generally low when polymer flooding alone is carried out $[18,19]$.

Thus, EOR methods have become urgent because traditional oil recovery techniques only obtain a limited portion of the original oil in place [20]. Among the novel EOR techniques, microbial enhanced oil recovery (MEOR) shows potential, and it was found that oil recovery of reservoirs can be increased by $20 \%$ through MEOR technology [21]. MEOR has wide application scope, simple process, good economic benefit, does not damage the oil layer, and does not pollute the environment [22-24]. It is a tertiary recovery technology and is considered to be one of the most effective EOR methods, especially for old and depleted oilfields. Over 1000 wells in the United States have been using MEOR technology to increase oilfield production, and $78 \%$ of them decreased water production and increased oil recovery [25]. The production of biosurfactants such as rhamnolipids is a reason for microbes to enhance oil recovery [26]. However, due to the heterogeneity of reservoir structure, only microbial flooding is inefficient, because the injected microbial fluids move along the high permeability layer with relatively low oil saturation, resulting in low oildisplacement efficiency [27]. In some studies, no obvious oil recovery was also observed if a short retention period was carried out after microbial flooding [28,29].

Ansai Oilfield, the first oilfield with 100 million tons of integrated ultra-low permeability on land in China, has typical "three-low" characteristics, and is known as a grindstone oilfield with "oil in wells but no flow in wells" [29]. Massive obvious micro-fractures are developed in this oilfield. After the production of continuous water injection, the oilfield has entered the late stage of high water cut [30]. The distribution of oil and water in the reservoir is complex and the remaining oil is highly dispersed in space, increasing the exploitation difficulty.

Considering polymer plugging and microbial flooding advantages and the "three-low" characteristics of the Ansai Oilfield, in this study, the combination of polymer plugging and microbial flooding was carried out to enhance oil recovery in oilfields with the Anai Oilfieldlike characteristics. Firstly, two highly biosurfactant-producing strains (a rhamnolipidproducing 8D and a lipopeptide-producing S4), were isolated from Ansai Oilfield (Yanan city, Shaanxi province, China). The fermentation broth of the two strains was proportioned to obtain a multicomponent microbial oil-displacing agent. A laboratory-based study was carried out to characterize the properties of the mixture of the two bacterial fermentation liquids and investigate the compatibility with polymer plugging. Then, the core physical model experiment was performed to examine the oil-displacement efficiency under the combined condition. This study provided a theoretical basis for enhancing oil recovery in heterogeneous low permeability oilfields.

\section{Materials and Methods}

\subsection{Materials and Strains}

All chemicals, solvents, and reagents used in this study were of analytical grade with a purity $>98 \%$ and obtained from the commercial supplier (AOBOXING Universeen Bio-tech, Beijing, China). The polymer purchased from Beijing Hengju Chemical Group Co., Ltd. (Beijing, China) was polyacrylamide with a hydrolysis rate of $27.4 \%$ (HPAM) 
and a molecular weight of $1.8 \times 10^{7}$. The dehydrated and degassed crude oil used in this study was obtained from Wangyao block in Chang 6 reservoir of Ansai Oilfield in China, which was a sandstone reservoir with a buried depth of $1100 \sim 1300 \mathrm{~m}$, formation pressure of $6.74 \mathrm{MPa}$, formation temperature $45^{\circ} \mathrm{C}$, and a viscosity of $8.36 \mathrm{mPa} \cdot \mathrm{s}$ at $45^{\circ} \mathrm{C}$. The formation water was separated from the oil well produced fluid. It was a calcium chloride water type mainly containing $\mathrm{Cl}^{-}, \mathrm{K}^{+}$, and $\mathrm{Ca}^{2+}$.

The strains used in this study were isolated from the production water of Wangyao block in Chang 6 reservoir of Ansai Oilfield and identified as P. aeruginosa 8D (CCTCC NO.M2011287) and B. subtilis S4 (CCTCC NO.M2011289) after the samples were grown in Luria-Bertani (LB) broth (10 $\mathrm{g}$ of peptone, $5 \mathrm{~g}$ of yeast extract, and $5 \mathrm{~g}$ of sodium chloride in $1 \mathrm{~L}$ of water) with $1 \mathrm{~g}$ of crude oil at $37{ }^{\circ} \mathrm{C}$ for $48 \mathrm{~h}$. These two bacterial strains were preserved in China's Center for Type Culture Collection (CCTCC). To prepare multicomponent microbial oil displacing agent (MMODA) for the core-flooding experiment, these two strains were respectively inoculated in different fermentation media to produce biosurfactant. The medium ( $\mathrm{pH}$ 7.0) for P. aeruginosa $8 \mathrm{D}$ fermentation was composed of $5.0 \mathrm{~g}$ of $\mathrm{NaNO}_{3}, 1.5 \mathrm{~g}$ of $\mathrm{KH}_{2} \mathrm{PO}_{4}, 1.2 \mathrm{~g}$ of $\mathrm{Na}_{2} \mathrm{HPO}_{4}, 0.6 \mathrm{~g}$ of $\mathrm{MgSO}_{4}, 0.036 \mathrm{~g}$ of $\mathrm{CaCl}_{2}, 0.00025 \mathrm{~g}$ of $\mathrm{FeCl}_{3}, 1.0 \mathrm{~mL}$ of trace mineral elements containing $\mathrm{MnSO}_{4}(39.9 \mathrm{mg} / \mathrm{L}), \mathrm{ZnSO}_{4} \cdot \mathrm{H}_{2} \mathrm{O}$ $(42.8 \mathrm{mg} / \mathrm{L})$, and $\left(\mathrm{NH}_{4}\right)_{6} \mathrm{MoO}_{24} \cdot 4 \mathrm{H}_{2} \mathrm{O}(34.7 \mathrm{mg} / \mathrm{L})$, and $20 \mathrm{~mL}$ of rapeseed oil in $1 \mathrm{~L}$ of water [31]. The medium for B. subtilis DN2 fermentation consisted of $0.5 \mathrm{~g}$ of $\mathrm{KH}_{2} \mathrm{PO}_{4}$, $1.5 \mathrm{~g}$ of $\mathrm{Na}_{2} \mathrm{HPO}_{4}, 1 \mathrm{~g}$ of NaCl, $0.2 \mathrm{~g}$ of $\mathrm{MgSO}_{4}, 5 \mathrm{~g}$ of $\mathrm{NH}_{4} \mathrm{Cl}, 10 \mathrm{~g}$ of glucose, and $3 \mathrm{~g}$ of yeast extract in $1 \mathrm{~L}$ of water. The mineral salt medium (MSM) for crude oil degradation was composed of $3 \mathrm{~g}$ of $\mathrm{NH}_{4} \mathrm{Cl}, 1.25 \mathrm{~g}$ of $\mathrm{K}_{2} \mathrm{HPO}_{4} \cdot 3 \mathrm{H}_{2} \mathrm{O}, 0.2 \mathrm{~g}$ of $\mathrm{MgSO}_{4} \cdot 7 \mathrm{H}_{2} \mathrm{O}, 0.5 \mathrm{~g}$ of $\mathrm{KH}_{2} \mathrm{PO}_{4}, 0.01 \mathrm{~g}$ of $\mathrm{CaCl}_{2}, 0.5 \mathrm{~g}$ of yeast extract in $1 \mathrm{~L}$ of water.

\subsection{Assays of P. aeruginosa 8D and B. subtilis S4 Oil-Displacement and Biosurfactant Production}

P. aeruginosa $8 \mathrm{D}$ and B. subtilis $\mathrm{S} 4$ were separately cultured in LB plates containing $1 \mathrm{~g}$ of crude oil for $48 \mathrm{~h}$ at $37^{\circ} \mathrm{C}$, and the colony growth and oil-displacement circles were observed and photographed. To further analyze the oil-displacement capacity, $1 \mathrm{~mL}$ of crude oil was added to the water surface in a Petri dish with a 9-cm diameter. After the two strains were separately fermented, $10 \mu \mathrm{L}$ of supernatant culture from the fermentation liquids was gently added in the center of the oil layer. The diameter of this clear zone correlated to biosurfactant activity and was also termed as oil-displacement activity.

The biosurfactants of P. aeruginosa $8 \mathrm{D}$ and B. subtilis $\mathrm{S} 4$ were detected as previously described [32,33]. In brief, both of the fermentation liquids were centrifugated at 8000 rpm for $10 \mathrm{~min}$. The supernatant was adjusted to 2.0 using $6 \mathrm{M} \mathrm{HCl}$, and extracted three times with an equal volume of ethyl acetate. The organic phase was combined and the crude biosurfactant was obtained by rotary evaporation. ESI-MS (Thermo, Waltham, MA, USA) was used to analyze the chemical components of the crude biosurfactants in the fermentation broth.

The rhamnolipids quantification in the fermentation liquid of P. aeruginosa $8 \mathrm{D}$ was carried out using the previous method [34]. The quantification of lipopeptide in the fermentation liquid of B. subtilis S4 was obtained by weighting the dry extract [35]. Briefly, after centrifugation, the supernatant was adjusted to $\mathrm{pH} 2.0$ and kept at $4{ }^{\circ} \mathrm{C}$ overnight. Followed centrifugation again, the precipitation obtained was dried in vacuum and extracted three times with dichloromethane. After removing dichloromethane in the extract in a rotary evaporator, the yellowish powder was obtained as a lipopeptide crude sample and weighted.

\subsection{The Preparation of MMODA and Performance Evaluation}

\subsubsection{The Preparation of MMODA}

To prepare MMODA with high oil-displacement activity, the fermentation liquids of the two strains were mixed with the following ratios (P. aeruginosa 8D:B. subtilis S4, v:v) of 1:1 (a-MMODA), 1:3 (b-MMODA), and 1:5 (c-MMODA). The optimal ratio was selected by evaluating the performance for oil-displacement. 


\subsubsection{Emulsion Activity Assay}

Emulsion activity was assessed by emulsification index EI24. To determine the emulsification index, $4 \mathrm{~mL}$ of different MMODAs were added to $6 \mathrm{~mL}$ of paraffin oil in a test tube with glass stopper, vigorously vortexed for $2 \mathrm{~min}$, and then kept for $24 \mathrm{~h}$. The height of emulsion layers was measured. Emulsification index EI24 was calculated with the following equation [36]:

EI24 $=($ Height of emulsion layer $/$ Height of total hydrophobic liquid height $) \times 100 \%$

\subsubsection{Surface Tension and Interfacial Tension}

JYW-200A surface tensiometer (Chengdu Lingdu INSTRUMENT, Chengdu, China) and SVT-20 rotary drop interfacial tensiometer (Beijing Dataphys Instruments, Beijing, China) were used to determine the surface tension and interfacial tension of the different MMODA at room temperature.

\subsubsection{Displacement Efficiency of Oil Sand}

Oil sand model was prepared as the previous method [37]. In brief, after $49 \mathrm{~mL}$ of water was added into a beaker (its weight was named as $\mathrm{M}_{0}$ ), the beaker was heated until $45^{\circ} \mathrm{C}$ and $1 \mathrm{~mL}$ of MMODA was dissolved in the water. After $3 \mathrm{~g}$ of oil sand was slowly added, gently shaked 10 times every $0.5 \mathrm{~h}$, and left for $24 \mathrm{~h}$, the upper liquid was carefully collected. When the remaining water was removed to constant weight at $110^{\circ} \mathrm{C}$, the weight of the beaker was denoted as $\mathrm{M}_{1}$. The oil-displacement efficiency was calculated according to the following formula:

$$
\mathrm{R}=\left(\mathrm{M}_{0}+3-\mathrm{M}_{1}\right) /\left(\mathrm{M}_{0}+3\right) \times 100 \%
$$

Which,

$\mathrm{R}$-Displacement efficiency, \%

$\mathrm{M}_{0}$-Weight of empty beaker, $\mathrm{g}$

$\mathrm{M}_{1}$-Weight of remaining oil sand and empty beaker, $\mathrm{g}$

\subsubsection{Degradation of Crude Oil}

Biodegradation of crude oil was performed in 500-mL Erlenmeyer flasks containing $200 \mathrm{~mL}$ of MSM and $10 \mathrm{~g}$ of crude oil as the only carbon source. After inoculation, the cultures were incubated in a rotary shaker with $180 \mathrm{rpm}$ at $30^{\circ} \mathrm{C}$. After seven days of growth, the residual crude oil was recovered by extracting the culture with $100 \mathrm{~mL}$ of petroleum ether three times. The amount of the residual crude oil was measured by the gas chromatographic analyzer (Agilent $6890 \mathrm{~N}$ ) equipped with a HP-5 capillary column ( $5 \%$ phenyl Methyl Siloxane, $30 \mathrm{~m} \times 320 \mu \mathrm{m} \times 0.25 \mu \mathrm{m}$ ) and an FID detector. The column temperature was held at $160{ }^{\circ} \mathrm{C}$ for $1 \mathrm{~min}$, raised from $160{ }^{\circ} \mathrm{C}$ to $260^{\circ} \mathrm{C}$ in $20^{\circ} \mathrm{C} / \mathrm{min}$ increments, and then held for $6 \mathrm{~min}$. The injector and transfer line temperatures were $250{ }^{\circ} \mathrm{C}$ and $300{ }^{\circ} \mathrm{C}$, respectively.

\subsubsection{Temperature Effects on MMODA}

Thirty milliliters of the selected MMODAs were respectively put into the incubator with various temperatures $\left(20,30,40,50,60\right.$, and $\left.70^{\circ} \mathrm{C}\right)$ for $12 \mathrm{~h}$, and then the surface tension was determined.

\subsubsection{Salt Effects on MMODA}

Salt tolerance experiments were performed in 50-mL Erlenmeyer flasks with $30 \mathrm{~mL}$ of the selected MMODA, and $10 \%, 12 \%, 14 \%, 16 \%, 18 \%$ or $20 \%$ (v:v) of $\mathrm{CaCl}_{2}$. The cultures were incubated in a rotary shaker with $180 \mathrm{rpm}$ at $45^{\circ} \mathrm{C}$ and kept for $2 \mathrm{~h}$. Then, the surface tension was determined. After $30 \mathrm{~g}$ of crude oil samples were supplemented and mixed with the above liquid, the viscosity was measured at $45^{\circ} \mathrm{C}$. 


\subsection{HPAM-MMODA Compatibility}

The compatibility of HPAM and MMODA was examined in 500-mL Erlenmeyer flasks containing $100 \mathrm{~mL}$ of the selected MMODA and $100 \mathrm{~mL}$ of 2000 ppm HPAM solution supplemented with $10 \%(v: v)$ crude oil samples as the only carbon source. The cultures were incubated in a rotary shaker with $150 \mathrm{rpm}$ at $45^{\circ} \mathrm{C}$. The control experiments were performed under the same conditions except for MMODA. The viscosity of the mixture was measured at regular intervals and the viscosity-time variation curve was drawn with viscosity as index.

To characterize the effect of HPAM on microbial growth, the method used was as mentioned above, and the control experiments were performed under the same conditions except for HPAM. After dilution, 3 aliquots of $100 \mu \mathrm{L}$ were used for the counting of colony-forming units (CFUs).

\subsection{Core Flooding Experiment}

The setup used for core flooding is shown in Figure 1. Three artificial three-layer heterogeneous core samples with the properties similar to Ansai Oilfield (the target reservoir) were prepared. The design size was $3.5 \mathrm{~cm} \times 3.5 \mathrm{~cm} \times 20 \mathrm{~cm}$. The thickness of relative high permeability layer in the center of the core was $1 \mathrm{~cm}$ and the permeability was $75 \mathrm{mD}$, which was used to simulate water channels. The relative low permeability layer (simulated matrix) on both sides of the core was $1.25 \mathrm{~cm}$ and the permeability was $10 \mathrm{mD}$. The main experimental steps are as follows. After the core samples were vacuumized and saturated with formation water, the pore volume (PV) and water phase permeability were measured (i.e., water saturation stage). Then, oil saturation was measured and the samples were aged in a temperature-controlled oven at $45{ }^{\circ} \mathrm{C}$ for $72 \mathrm{~h}$ (i.e., oil saturation stage). During the oil recovery process, the temperature was kept at $45^{\circ} \mathrm{C}$ with a flow rate at $0.05 \mathrm{~mL} / \mathrm{min}$. Water flooding was conducted until water cut reached to $98 \%$, and then followed by $1 \mathrm{PV}$ HPAM injection (polymer concentration and viscosity equal to $2000 \mathrm{mg} / \mathrm{L}$ and $38.24 \mathrm{mPa} \cdot \mathrm{s}$ ) for sample 1, $1 \mathrm{PV}$ b- MMODA injection followed by shut-in for $7 \mathrm{~d}$ at $45^{\circ} \mathrm{C}$ for sample 2 . For sample 3, 0.5 PV HPAM was injected, followed by 0.5 PV b-MMODA and then shut-in for seven days at $45^{\circ} \mathrm{C}$. Followed by post-water flooding until the water cut reached to $98 \%$, the performance of pressure difference and recovery factor were analyzed.

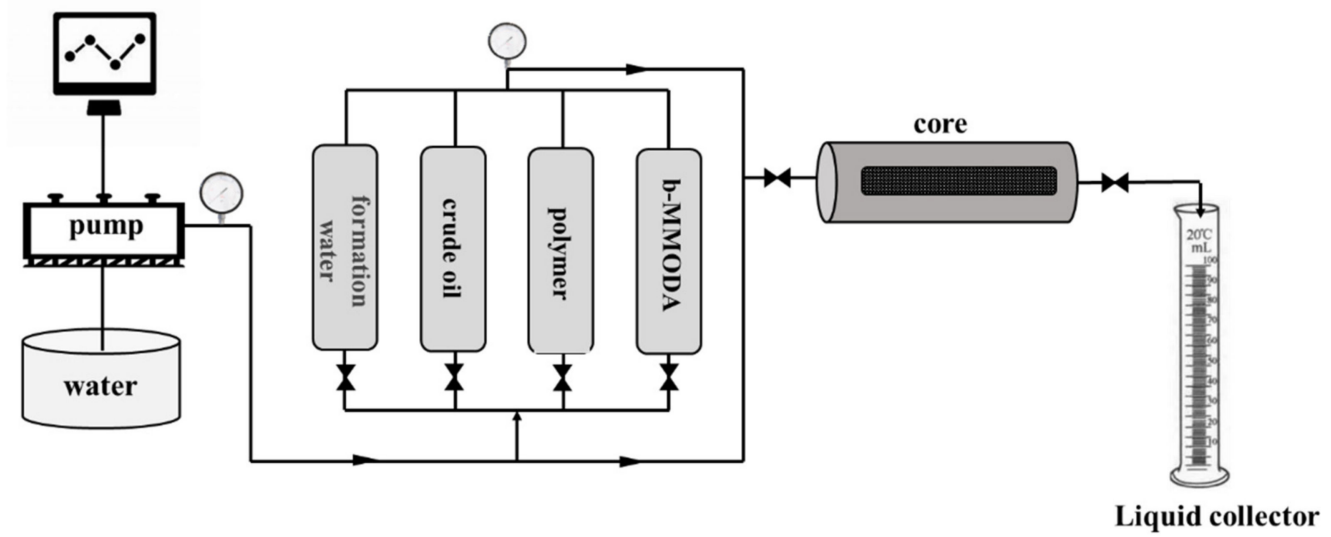

Figure 1. Experimental setup for core flooding.

\section{Results}

\subsection{Oil-Displacement and Biosurfactant Analysis of P. aeruginosa $8 D$ and B. subtilis $S 4$}

To evaluate the adaptability of the strains $8 \mathrm{D}$ and $\mathrm{S} 4$ to the target reservoir and their effects on crude oil, the properties of the strains under different conditions were characterized, including oil-displacement activity and qualitative and quantitative analyses of biosurfactants. The results showed that the colony of $8 \mathrm{D}$ was small, round, and transparent, 
and S4 was white and flat with rough edges and round opacity. They both showed obvious oil-discharge capacity in the medium with crude oil addition (Figure 2A,B). If the oil forms a clear zone in the Petri dish with crude oil, it indicates the presence of biosurfactant in the culture supernatant. When the supernatants of fermentation liquids were added in the Petri dish with crude oil, strain $8 \mathrm{D}$ showed a $7.5 \mathrm{~cm}$ diameter of clear zone and that of S4 was $3.3 \mathrm{~cm}$ (Figure 2C,D), indicating that the two strains might produce biosurfactants. The analysis of ESI-MS showed that the biosurfactants produced by strain 8D were mainly Rha- Rha- $\mathrm{C}_{10}-\mathrm{C}_{10}$ and Rha-Rha- $\mathrm{C}_{10}$ rhamnolipids, and strain S4 synthesized C15 lturin A lipopeptide (Figure 3). Quantification results showed that the concentration of rhamnolipids and lipopeptide was $30.23 \mathrm{~g} / \mathrm{L}$ and $3.56 \mathrm{~g} / \mathrm{L}$, respectively.
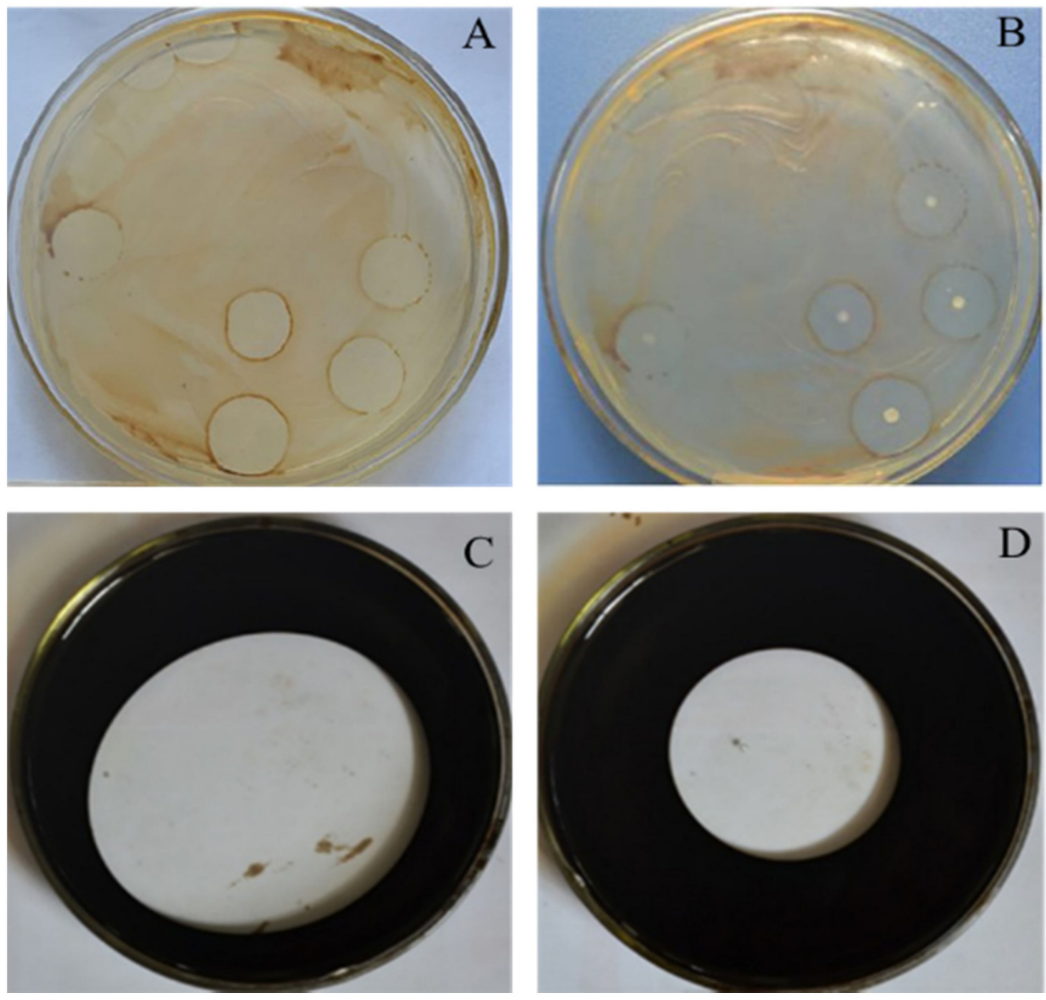

Figure 2. Oil-displacement performance of P. aeruginosa 8D and B. subtilis S4. (A and B) Oil-discharge capacity of $P$. aeruginosa $8 \mathrm{D}$ and B. subtilis S4. (C and D) Oil spreading test for detection of biosurfactants of the fermentation broths of P. aeruginosa 8D and B. subtilis S4.

\subsection{The Preparation of MMODA and the Evaluation of Oil-Displacement Performance}

Considering the complexity of the formation environment and the diversity of bacterial community structure, a single strain may not be able to grow well. Therefore, the two bacterial fermentation liquids were mixed and used. It is known that bacteria cells and the produced biosurfactant are beneficial for oil-displacement [38-40], so the fermentation broths of the two strains were directly mixed in a certain proportion of 1:1, 1:3 and 1:5, respectively. The surface tension, oil-water interfacial tension, emulsification effects, and displacement efficiency of oil sand were measured under different conditions. The results showed that compared with the fermentation broth of the individual strain, the mixing ratio of 1:3 (b-MMODA) showed the optimal effects with $88.87 \%$ emulsification ratio, $95.23 \%$ oildisplacement efficiency, $19.63 \mathrm{mN} / \mathrm{m}$ surface tension, and $0.015 \mathrm{mN} / \mathrm{m}$ oil-water interfacial tension (Table 1). 

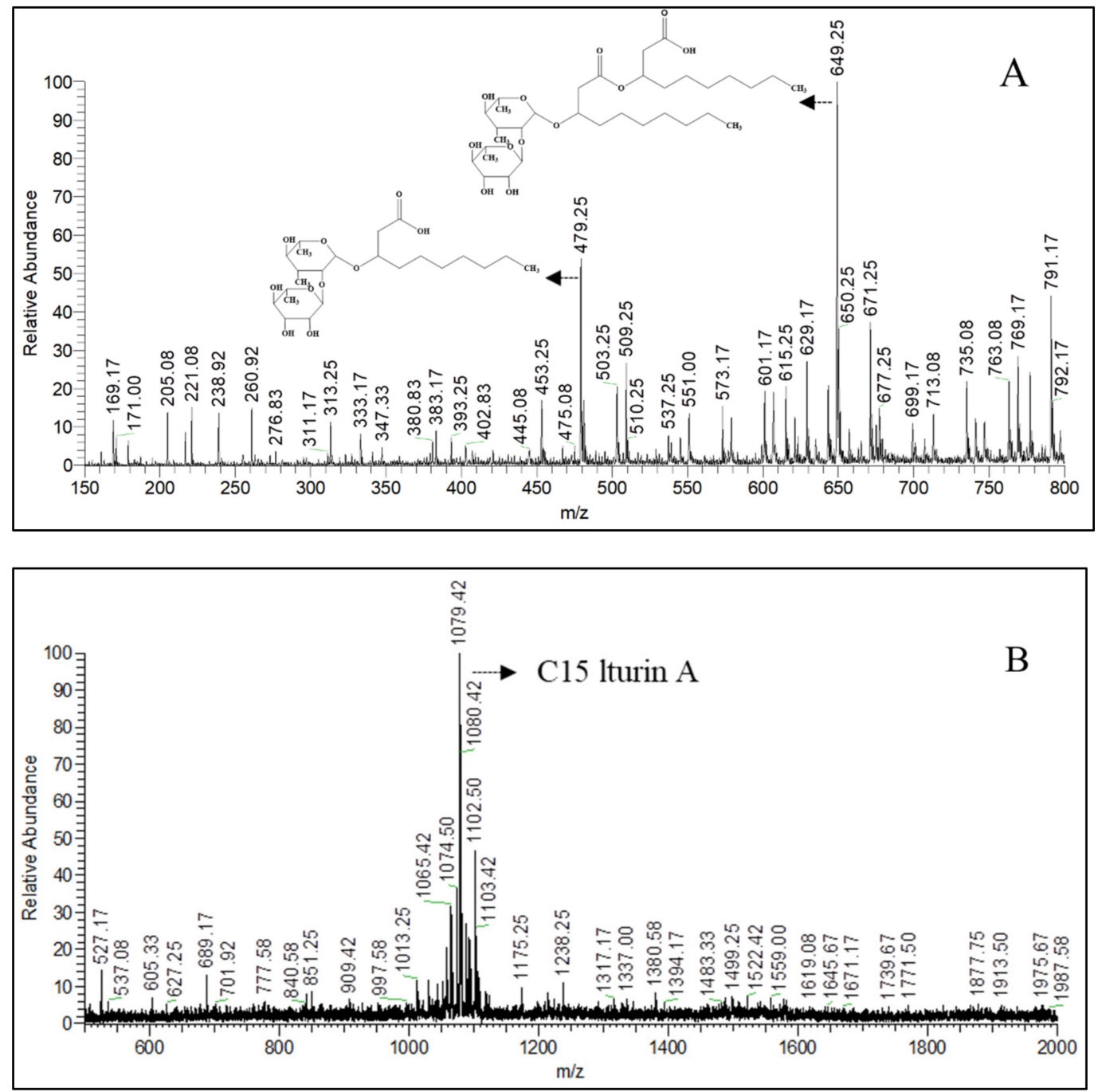

Figure 3. ESI-MS analysis of P. aeruginosa 8D S4 (A) and B. subtilis S4 (B) fermentation extracts.

Table 1. Emulsification index, surface tension, interfacial tension, and displacement efficiency of different samples.

\begin{tabular}{ccccc}
\hline Sample & $\begin{array}{c}\text { EI24 } \\
\mathbf{( \% )}\end{array}$ & $\begin{array}{c}\text { Surface Tension } \\
\mathbf{( m N / m )}\end{array}$ & $\begin{array}{c}\text { Interfacial Tension } \\
(\mathbf{m N} / \mathbf{m})\end{array}$ & $\begin{array}{c}\text { Displacement } \\
\text { Efficiency } \mathbf{( \% )}\end{array}$ \\
\hline control & $0 \pm 0$ & $72.89 \pm 0.19$ & $18.902 \pm 0.005$ & $0 \pm 0$ \\
8D & $80.87 \pm 0.54$ & $25.33 \pm 0.24$ & $0.180 \pm 0.005$ & $87.56 \pm 0.41$ \\
S4 & $55.32 \pm 0.35$ & $32.89 \pm 0.02$ & $15.872 \pm 0.107$ & $60.87 \pm 0.31$ \\
a-MMODA & $83.56 \pm 0.40$ & $25.45 \pm 0.17$ & $0.030 \pm 0.002$ & $90.77 \pm 0.65$ \\
b-MMODA & $88.87 \pm 0.97$ & $19.94 \pm 0.12$ & $0.012 \pm 0.001$ & $95.23 \pm 0.51$ \\
c-MMODA & $77.24 \pm 0.58$ & $28.67 \pm 0.27$ & $0.080 \pm 0.001$ & $85.01 \pm 0.07$ \\
\hline
\end{tabular}

To evaluate the adaptability of b-MMODA to the target reservoir, the salt and temperature tolerance and the degradation rate of crude oil were investigated. A temperature test demonstrated that temperatures between $20^{\circ} \mathrm{C}$ and $70{ }^{\circ} \mathrm{C}$ had no significant effects on the surface tension of the b-MMODA (Table 2). In order to clarify the effects of salt on b-MMODA, the surface tensions of solutions at different salt concentrations were tested. It showed that the solutions were not affected by the addition of $\mathrm{CaCl}_{2}$ at the tested conditions, indicating a high salt tolerance (Figure 4). In addition, the oil viscosity was kept $150 \mathrm{mPa} \cdot \mathrm{s} \pm 50 \mathrm{mPa} \cdot \mathrm{s}$ within the salt concentration at a range of $10 \sim 22 \%$. In addition, 
b-MMODA displayed a good biodegradation of crude oil, especially for heavy components $\left(\mathrm{C}_{29}-\mathrm{C}_{36}\right)$, with a degradation rate of $82.6 \%$ (Figure 5).

Table 2. The surface tension of b-MMODA under various temperature.

\begin{tabular}{cccccccc}
\hline Temperature $\left({ }^{\circ} \mathrm{C}\right)$ & $\mathbf{2 0}$ & $\mathbf{3 0}$ & $\mathbf{4 0}$ & $\mathbf{5 0}$ & $\mathbf{6 0}$ & $\mathbf{7 0}$ \\
\hline Surface tension $(\mathrm{mN} / \mathrm{m})$ & 20.13 & 20.11 & 20.12 & 20.13 & 20.15 & 20.10 \\
\hline
\end{tabular}

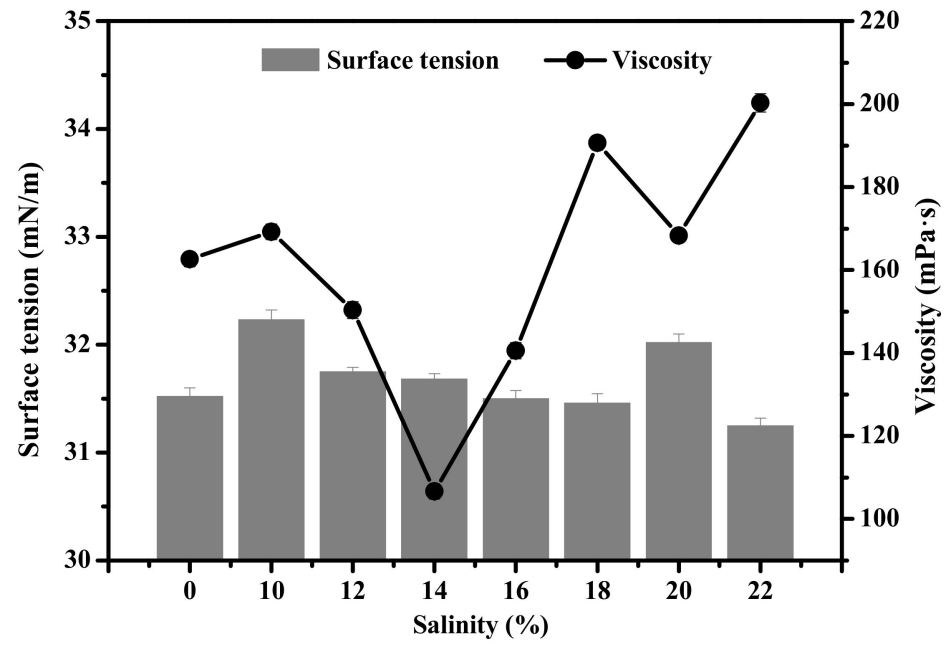

Figure 4. The effect of salinity on the surface tension of MMODA.

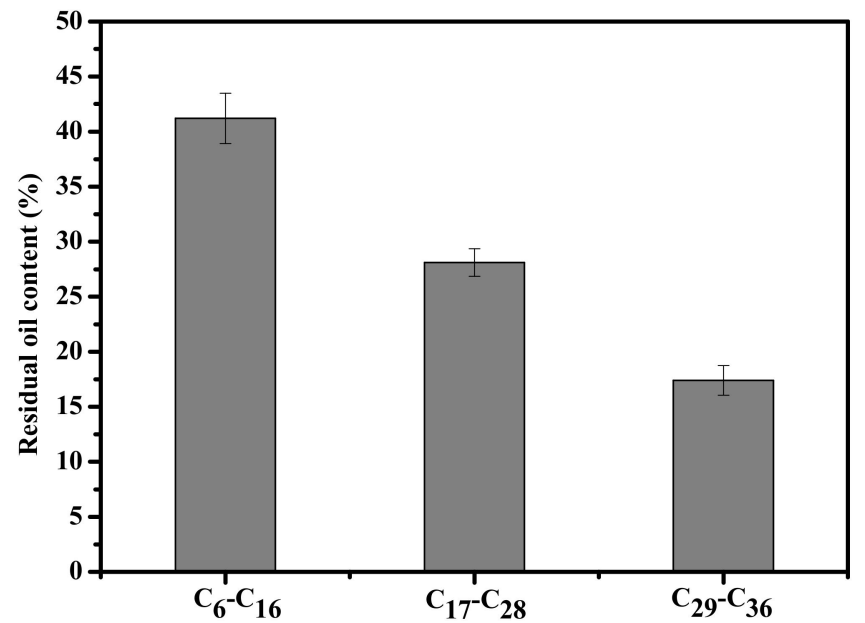

Figure 5. Residual rate of crude oil after degradation by b-MMODA.

\subsection{Compatibility Assay of HPAM and b-MMODA}

The compatibility of HPAM and b-MMODA was examined by monitoring the change of solution viscosity and bacterial viability over a period in the medium with crude oil. As shown in Figure 6, before b-MMODA addition the viscosity of crude oil system containing $2000 \mathrm{ppm}$ HPAM was $38.1 \mathrm{mPa} \cdot \mathrm{s}$ and after b-MMODA addition the viscosity decreased to $28.5 \mathrm{mPa} \cdot \mathrm{s}$, indicating that b-MMODA was able to change the viscosity of the polymercrude oil system. In addition, with the extension of the time the viscosity of solution rapidly decreased to about $50 \%$ within the first two days and then remained constant in the tested 34-d period. Taken together, the microbial solution had no obvious effect on the viscosity of the polymer-crude oil system, indicating the two had good compatibility. The effects of the polymer addition on the bacterial growth were also tested. The result showed that no significant difference of the growth curves of the two bacteria was observed with or without polymer addition and the microbial concentration was maintained at 
about $1.2 \times 10^{8} \mathrm{CFU} / \mathrm{mL}$ (Figure 6), indicating the two bacteria could grow in the presence of HPAM.

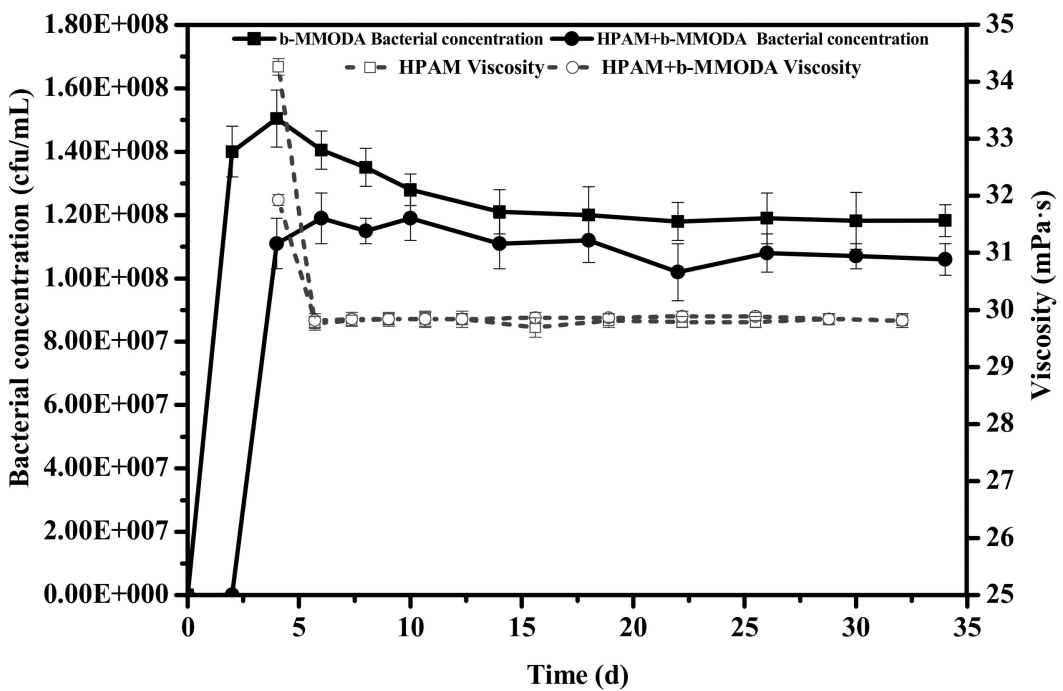

Figure 6. Compatibility of HPAM with b-MMODA.

\subsection{Core Flooding Experiment}

The physical model of core flooding was carried out in the laboratory to examine the effects of polymer flooding and microbial flooding in combination. The sandstone core was used for conducting a displacement process. Physical properties of the artificial core samples were shown in Table 3. Water flooding, polymer injection, microbial injection, and post-water flooding were performed sequentially at the test reservoir temperature $\left(45^{\circ} \mathrm{C}\right)$, and the oil recovery efficiency and the pressure variations across the core were recorded.

Table 3. Physical properties of the core samples used in the core flooding experiment.

\begin{tabular}{lccccc}
\hline & $\begin{array}{c}\text { Length } \\
(\mathbf{m m})\end{array}$ & $\begin{array}{c}\text { Inner Diameter } \\
\mathbf{( m m})\end{array}$ & $\begin{array}{c}\text { Porosity } \\
\mathbf{( \% )}\end{array}$ & $\begin{array}{c}\text { Oil Saturation } \\
\mathbf{( \% )}\end{array}$ & Injection Formula \\
\hline Sample 1 & 19.40 & 35.10 & 25.57 & 64.89 & 1 PV HPAM \\
Sample 2 & 19.90 & 35.10 & 23.64 & 63.50 & 1 PV b-MMODA \\
Sample 3 & 20.13 & 34.90 & 18.59 & 60.28 & $\begin{array}{c}\text { P.5 PV HPAM + 0.5 } \\
\text { PV b-MMODA }\end{array}$ \\
\hline
\end{tabular}

During water flooding no obvious change was observed for water flooding recovery of the three core samples, and they were $30.25 \%, 33.3 \%$, and $33.9 \%$, respectively (Figure 7 ). With continuous water injection, the pressure dropped and remained at a relatively low level. This might be because the saturated oil in the core was displaced by water.

In the second process of injection, the oil recovery and pressure displayed remarkable difference due to various fluid injection. The results of oil recovery showed that after water flooding until the limit water cut, polymer flooding and microbial flooding further improved oil recovery. The injection of HPAM (1 PV) in sample 1 increased $9.87 \%$ of oil recovery, and b-MMODA (1 PV) in sample 2 increased $14.85 \%$. However, after the injection of $0.5 \mathrm{PV}$ polymer followed by $0.5 \mathrm{PV}$ b-MMODA, the oil recovery was as high as $24.88 \%$, indicating that the oil recovery of polymer plugging followed by microbial flooding was better than single polymer flooding or microbial flooding.

During the final step of post-water flooding, a further increase in oil recovery was observed in the tested cores. The increase rate of the post-water efficiency of sample 1 , sample 2 , and sample 3 is $12.3 \%, 13.63 \%$, and $15.04 \%$, respectively. 


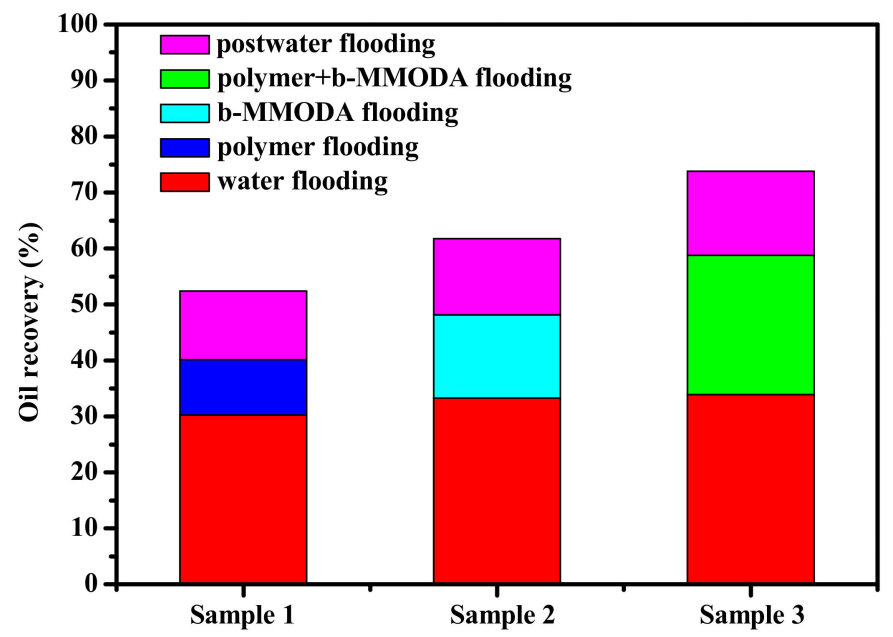

Figure 7. Oil recovery of the core flooding: Sample 1, water flooding-polymer flooding-postwater flooding; Sample 2, water flooding-b-MMODA flooding- postwater flooding; Sample 3, water flooding-polymer followed by b-MMODA flooding-postwater flooding.

\section{Discussion}

Biosurfactants have been proved to be beneficial to enhance oil recovery. In this study, it showed that the two isolated strains P. aeruginosa $8 \mathrm{D}$ and B. subtilis $\mathrm{S} 4$ were capable of producing biosurfactant at a high level [41,42]. Biosurfactants play a role in the oil-water interface to increase the wettability of oil-bearing rock and make the residual oil in the rock hole easy to desorp [43,44]. In addition, biosurfactants have strong emulsification and viscosity reduction effects in crude oil, and oil-displacement efficiency is 3.5-8 times higher than chemical synthetic surfactants. The highly biosurfactants-producing ability indicated that the selected bacteria might have good effects in oil-displacement.

In order to increase bacterial diversity to play an oil-displacement role in the target oil reservoirs with heterogeneous low permeability, the combination of two bacteria was considered. The fermentation broth of the two strains was proportioned to obtain a multicomponent microbial oil displacing agent. The results of oil-displacement showed that when two bacterial fermentation liquids were mixed at the ratio of 1:3 (v:v), they displayed the optimum surface activity, emulsification, and oil-displacement. This was probably because when the rhamnolipid and lipopeptide in the fermentation broth were mixed, micelles were easier to form to decrease the critical micelle concentration with the number of carbon atoms increased in the system. The two components might be spontaneously attracted in the surface adsorption layer to reduce the surface and interfacial tension of the solution. A previous study investigated the equilibrium interfacial tension (IT) and dynamic IT rhamnolipid-sophorolipid mixed biosurfactant system with the mass fraction of sodium carbonate $\left(\mathrm{Na}_{2} \mathrm{CO}_{3}\right)$ at range of $0.0 \% \sim 1.2 \%$, and evaluated oil displacement through the core simulation experience, which indicated there were synergistic effects for enhancing oil recovery between the components in the rhamnolipid/sophorolipid $/ \mathrm{Na}_{2} \mathrm{CO}_{3}$ system [45]. We speculated that the combination of rhamnolipid and lipopeptide might have a similar synergistic effect. In addition, b-MMODA displayed a good biodegradation of crude oil of heavy components $\left(\mathrm{C}_{29}-\mathrm{C}_{36}\right)$. The fluidity of crude oil was improved, which was conducive to the improvement of oil recovery. The adaptability of b-MMODA to the target reservoir and the compatibility with HPAM were studied. The good adaptability of b-MMODA to the target reservoir and its capabilities for viscosity reduction and crude oil emulsification indicated a promising potential for application in MEOR.

The physical model of core flooding in the laboratory were carried out to examine the effects of polymer-based plugging and microbial flooding combination. The results showed that the strategy of polymer plugging followed by microbial flooding was advisable for heterogeneous low permeability reservoirs. A similar study was conducted previously and found that injection of microbial injection followed by polymeric HPAM/Cr (III) plugging 
system was able to recover an additional 57.2\% of the original oil [46]. This was different from our results of a polymer injection followed by water flooding and microbial flooding. Importantly, no information about the heterogeneity of the cores used in the experiments was provided, and it was not comparable with our results. We speculated that due to the heterogeneity of the core, injection water passed through the macropore channels and bypassed the low permeability channel, resulting in low sweep efficiency. When polymer flooding was performed, the addition of the polymer plugged the high permeability zone and increased the viscosity of injected water and the seepage resistance of high permeability zones. The polymer can improve the sweep efficiency and play a role in profile control, which is conducive to the subsequent microbial bacterial fluid to enter the suitable position and interact with crude oil so as to effectively produce the residual oil of low permeability zones. Our results showed that the injection of b-MMODA showed a higher oil recovery than the polymer injection, and it was speculated that this was because there was an incubation (shut-in) period after the injection of b-MMODA [27]. This incubation allowed the bacteria to grow inside the core and produce some useful substances to release the trapped oil. A sharp increase of pressure at the injection point of polymer and a slight increase at the b-MMODA injection for plugging were observed, indicating a pressure increase (Figure 8). For sample 1, with the injection of HPAM, the pressure rose sharply. For sample 3, with the injection of HPAM followed by b-MMODA, there was a slight pressure drop when b-MMODA was injected, which was probably attributable to the interaction between the biosurfactant with the residual oil in the porous cores. The increasing rate of post-water flooding with polymer flooding followed by microbial flooding was higher than that of microbial flooding or polymer flooding alone. This might be because the injected microbial cells and their metabolites played roles in crude oil, which is consistent with the result that the post-water flooding efficiency after b-MMODA flooding was higher than that of polymer flooding.

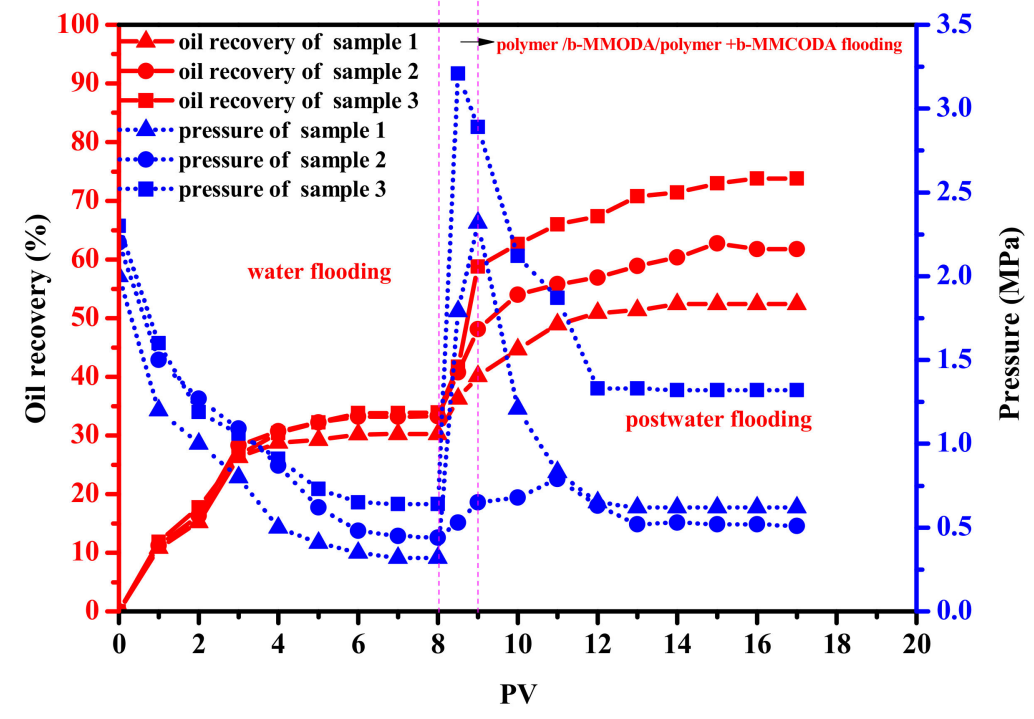

Figure 8. Recovery and pressure comparison for the studied cases: Sample 1, polymer flooding; Sample 2, b-MMODA flooding; Sample 3, polymer flooding followed by b-MMODA flooding.

\section{Conclusions}

In this study, a multicomponent microbial component oil-displacing agent (b-MMODA) and its combination with polymer hydrolysis polyacrylamide (HPAM) were studied. Two highly biosurfactants-producing strains, P. aeruginosa $8 \mathrm{D}$ and B. subtilis S4, were isolated. The mixing ratio of 1:3 (v/v) for with $8 \mathrm{D}$ and $S 4$ fermentation broth showed optimal emulsification, displacement efficiency, surface tension, and oil-water interfacial tension. The compatibility of HPAM with b-MMODA was studied, and it was found that they displayed 
good compatibility. A physical model was used for the core flooding experiment, and the results showed that polymer injection followed by b-MMODA injection significantly improved the displacement efficiency of heterogeneous low permeability reservoirs compared with polymer flooding or microbial flooding alone. In summary, for heterogeneous low-permeability reservoirs, the strategy of polymer plugging high-depth pores first and then initiating microbial oil displacement was a promising EOR technique. However, some details should be further studied to provide a basis for field application, such as optimization of the polymer concentrations, and the injection volume and injection time investigation of polymers and microbes, for example.

Author Contributions: Conceptualization, S.X. and S.W.; methodology, S.X. software, S.X. validation, S.X., Y.Z. and C.Z.; formal analysis, Y.Z. and G.Z.; investigation, S.X. and C.Z.; resources, S.X.; data curation, S.X. and G.Z.; writing-original draft preparation, S.X.; writing-review and editing, S.X., Y.Z. and S.W.; visualization, C.Z.; supervision, F.C. and S.W.; project administration, F.C. and S.W.; funding acquisition, F.C. and S.W. All authors have read and agreed to the published version of the manuscript.

Funding: This study was supported by grants from National Key R\&D Program of China (2021YFC1808902); the National Natural Science Foundation of China (31770152); Key Project on Social Development of Science and Technology in Shaanxi Province (2017ZDXM-SF-102); and Key Science and technology Innovation Team project of Shaanxi Province (2016KCT-12). The funders had no role in study design, data collection and interpretation, or the decision to submit the work for publication.

Institutional Review Board Statement: Not applicable.

Informed Consent Statement: Not applicable.

Data Availability Statement: Not applicable.

Conflicts of Interest: The authors declare no conflict of interest.

\section{References}

1. Alvarado, V.; Manrique, E. Enhanced Oil Recovery: An Update Review. Energies 2010, 3, 1529-1575. [CrossRef]

2. Cao, J.; Song, T.; Zhu, Y.; Wang, S.; Wang, X.; Lv, F.; Jiang, L.; Sun, M. Application of Amino-Functionalized Nanosilica in Improving the Thermal Stability of Acrylamide-Based Polymer for Enhanced Oil Recovery. Energy Fuels 2018, 32, $246-254$. [CrossRef]

3. Maurya, N.K.; Kushwaha, P.; Mandal, A. Studies on interfacial and rheological properties of water soluble polymer grafted nanoparticle for application in enhanced oil recovery-ScienceDirect. J. Taiwan Inst. Chem. Eng. 2017, 70, 319-330. [CrossRef]

4. Intek, I.J.A.R. Review of Emerging Resources: U. S. Shale Gas and Shale Oil Plays. In All Reports \& Publications; U.S. Department of Eneergy: Washington, DC, USA, 2011.

5. Dongkun, L.; Youjin, D. China's low-permeability gas resources await development. Oil Gas J. 2009, 107, 37-39.

6. Zhang, N. Development Characteristics and Development Technology Analysis of Low Permeability Oilfield. J. Phys. Conf. Ser. 2020, 1649, 012021-012025. [CrossRef]

7. Song, H.; Huang, X.; Lou, Y. Study on the effect of fracture characteristics to ultra-low permeability reservoirs development. In Proceedings of the 2011 Second International Conference on Mechanic Automation and Control Engineering, Inner Mongolia, China, 15-17 July 2011; pp. 3559-3562.

8. Bai, Y.B.; Zhang, Q. Characteristics and assessment of the Chang 2 low permeability sandstone reservoir in the Dingbian oilfield of Ordos Basin. Tezhong Youqicang Spec. Oil Gas Reserv. 2011, 18, 56-59.

9. Sheng, J.; Leonhardt, B.; Al Azri, N.S. Status of Polymer-Flooding Technology. J. Can. Pet. Technol. 2015, 54, 116-126. [CrossRef]

10. Wang, C.W. Discussion on the Application of EOR Technology in Oil Field. J. Phys. Conf. Ser. 2020, 1533, 022083. [CrossRef]

11. Wang, Y.L.; Li, T.; Fu, Z.G.; Liu, S.X.; Yu, B.L.; Sun, S.Y. The Research on Effect Factors of the Polymer Flooding in Low Permeability Reservoir of Daqing Oilfield. Adv. Mater. Res. 2011, 383-390, 3809-3813. [CrossRef]

12. Yan, H.; Wei, J.; Li, M.; Zhang, M.; Zhang, J.; Zhang, Q. Application of polymer microsphere flooding in L1 block of Jiyuan Oilfield. Petrochem. Ind. Technol. 2018, 4, 187-189.

13. Cui, C.; Zhou, Z.; He, Z. Engineering. Enhance oil recovery in low permeability reservoirs: Optimization and evaluation of ultra-high molecular weight HPAM/phenolic weak gel system. J. Pet. Sci. Eng. 2020, 195, 107908. [CrossRef]

14. Zhang, L.; Khan, N.; Pu, C. A New Method of Plugging the Fracture to Enhance Oil Production for Fractured Oil Reservoir using Gel Particles and the HPAM/Cr3+ System. Polymer 2019, 11, 446. [CrossRef] [PubMed] 
15. Kamal, M.S.; Sultan, A.; Al-Mubaiyedh, U.A.; Hussein, I.A. Review on Polymer Flooding: Rheology, Adsorption, Stability, and Field Applications of Various Polymer Systems. Polym. Rev. 2015, 55, 491-530. [CrossRef]

16. Feng, R.; Xue, S.; Chen, J.; Guo, Y.; Pu, D. Synthesis and solution properties of alkali-soluble hydrophobically associating terpolymer P(AM/AA/BEM). Oilfield Chem. 2017, 34, 165-170.

17. Wang, W.; Lu, X. Property Evaluation of Eor [Enhanced Oil Recovery] Technology by Means of Expansive Granular Crosslinked Polymer. In Proceedings of the SPE Production and Operations Symposium, Oklahoma City, OK, USA, 4 April 2009. [CrossRef]

18. Wang, W.; Yue, X.-A.; Chen, Y.-X. A Laboratory Feasibility Study of Surfactant-Polymer Combinational Flooding in Low Permeability Reservoirs. J. Dispers. Sci. Technol. 2013, 34, 639-643. [CrossRef]

19. Fan, Z.; Wang, M.; Jigang, J.; Wang, X. Study on Oil Displacement Efficiency of Binary Compound Flooding in Heterogeneous Reservoir. Energy Power Eng. 2015, 7, 571-574. [CrossRef]

20. Corredor, L.M.; Aliabadian, E.; Husein, M.; Chen, Z.; Maini, B.; Sundararaj, U. Heavy oil recovery by surface modified silica nanoparticle/HPAM nanofluids. Fuel. 2019, 252, 622-634. [CrossRef]

21. Eldeen, A.; Alhadi, A.; Mergani, M.A. Microbial Enhanced Oil Recovery (MEOR). Environmental Science. 2013. Available online: http:/ /api.uofk.edu:8080/api/core/bitstreams/22b6c57f-2e5b-47ad-86b2-cbb0354e6c2c/ content (accessed on 26 December 2021).

22. She, H.; Kong, D.; Li, Y.; Hu, Z.; Guo, H. Recent Advance of Microbial Enhanced Oil Recovery (MEOR) in China. Geofluids 2019, 2019, 1871392. [CrossRef]

23. Vishnyakov, V.; Suleimanov, B.; Salmanov, A.; Zeynalov, E. Microbial enhanced oil recovery (MEOR). In Primer on Enhanced Oil Recovery; Gulf Professional Publishing: Houston, TX, USA, 2020; pp. 161-169.

24. Gudiña, E.J.; Pereira, J.F.; Rodrigues, L.R.; Coutinho, J.; Teixeira, J. Isolation and study of microorganisms from oil samples for application in Microbial Enhanced Oil Recovery. Int. Biodeterior. Biodegrad. 2012, 68, 56-64. [CrossRef]

25. Patel, J.; Borgohain, S.; Kumar, M.; Rangarajan, V.; Somasundaran, P.; Sen, R. Recent developments in microbial enhanced oil recovery. Renew. Sustain. Energy Rev. 2015, 52, 1539-1558. [CrossRef]

26. Mcinerney, M.J.; Marsh, T.L.; Zhang, X.; Knapp, R.M.; Nagle, D.P., Jr.; Sharma, P.K.; Jackson, B.E. Development of More Effective Biosurfactants for Enhanced Oil Recovery. Office of Scientific \& Technical Information Technical Reports; U.S. Department of Energy: Tulsa, OK, USA, 2003.

27. Halim, A.Y.; Nielsen, S.M.; Lantz, A.E.; Suicmez, V.S.; Lindeloff, N.; Shapiro, A. Investigation of spore forming bacterial flooding for enhanced oil recovery in a North Sea chalk Reservoir. J. Pet. Sci. Eng. 2015, 133, 444-454. [CrossRef]

28. Wang, L.Y.; Gao, C.X.; Mbadinga, S.M.; Zhou, L.; Liu, J.F.; Gu, J.D.; Mu, B.Z. Characterization of an alkane-degrading methanogenic enrichment culture from production water of an oil reservoir after 274 days of incubation. Int. Biodeterior. Biodegrad. 2011, 65, 444-450. [CrossRef]

29. Bi, Y.Q.; Yu, L.; Huang, L.X.; Ma, T.; Xiu, J.L.; Yi, L.N. Microscopic profile control mechanism and potential application of the biopolymer-producing strain FY-07 for microbial enhanced oil recovery. Pet. Sci. Technol. 2016, 34, 1952-1957. [CrossRef]

30. Sakthipriya, N.; Doble, M.; Sangwai, J.S. Action of biosurfactant producing thermophilic Bacillus subtilis on waxy crude oil and long chain paraffins. Int. Biodeterior. Biodegrad. 2015, 105, 168-177. [CrossRef]

31. Nie, M.; Yin, X.; Ren, C.; Wang, Y.; Xu, F.; Shen, Q. Novel rhamnolipid biosurfactants produced by a polycyclic aromatic hydrocarbon-degrading bacterium Pseudomonas aeruginosa strain NY3. Biotechnol. Adv. 2010, 28, 635-643. [CrossRef]

32. Yin, H.; Qiang, J.; Jia, Y.; Ye, J.; Peng, H.; Qin, H.; Zhang, N.; He, B. Characteristics of biosurfactant produced by Pseudomonas aeruginosa S6 isolated from oil-containing wastewater. Process Biochem. 2009, 44, 302-308. [CrossRef]

33. Pecci, Y.; Rivardo, F.; Martinotti, M.G.; Allegrone, G. LC/ESI-MS/MS characterisation of lipopeptide biosurfactants produced by the Bacillus licheniformis V9T14 strain. Biol. Mass Spectrom. 2010, 45, 772-778. [CrossRef]

34. Gai, L.X.; Song, K.P. Ratio and Content of Rhamnolipid Determined using Sugar Development Process. Biotechnology 2010, 20, 33-37.

35. Biniarz, P.; Łukaszewicz, M. Direct quantification of lipopeptide biosurfactants in biological samples via HPLC and UPLC-MS requires sample modification with an organic solvent. Appl. Microbiol. Biotechnol. 2017, 101, 4747-4759. [CrossRef]

36. Cooper, D.G.; Goldenberg, B.G. Surface-Active Agents from Two Bacillus Species. Appl. Environ. Microbiol. 1987, 53, 224-229. [CrossRef]

37. Zhang, F.; She, Y.H. Quantitative and qualitative analysis of biosurfactant by oil spreading method. Chem. Eng. 2005, 1, 1002-1124. [CrossRef]

38. Tabatabaee, A.; Assadi, M.M.; Noohi, A.A.; Sajadian, V.A. Engineering. Isolation of Biosurfactant Producing Bacteria from Oil Reservoirs. J. Environ. Health Sci. Eng. 2005, 2, 6-12.

39. Al-Bahry, S.; Al-Wahaibi, Y.; Elshafie, A.; Al-Bemani, A.; Joshi, S.; Al-Makhmari, H.; Al-Sulaimani, H. Biosurfactant production by Bacillus subtilis B20 using date molasses and its possible application in enhanced oil recovery. Int. Biodeterior. Biodegrad. 2013, 81, 141-146. [CrossRef]

40. Mcinerney, M.J.; Jenneman, G.E.; Knapp, R.M. Biosurfactant and Enhanced Oil Recovery. U.S. Patent No. 4,522,261 A, 11 June 1985.

41. Lopes, P.; Montagnolli, R.N.; Cruz, J.M.; Lovaglio, R.B.; Bidoia, E.D.J.W.; Valorization, B. Production of Rhamnolipids from Soybean Soapstock: Characterization and Comparation with Synthetics Surfactants. Waste Biomass Valoriz. 2021, 12, $2013-2023$. [CrossRef] 
42. Meena, K.R.; Tandon, T.; Sharma, A.; Kanwar, S.S. Lipopeptide antibiotic production by Bacillus velezensis KLP2016. J. Appl. Pharm. Sci. 2018, 8, 91-98.

43. Fang, W. Preparation and properties of low interfacial tension biosurfactant solutions for eor. Oilfield Chem. 1994, 1, 66-69.

44. Joshi, S.; Al-Wahaibi, Y.M.; Al-Bahry, S.N.; Elshafie, A.E.; Al-Bemani, A.; Al-Bahri, A.; Al-Mandhari, M.S. Production, Characterization, and Application of Bacillus licheniformis W16 Biosurfactant in Enhancing Oil Recovery. Front. Microbiol. 2016, 7, 1853. [CrossRef]

45. Zheng, J.P.; Liang, S.K.; Shi, X.Y.; Lin, J.Z.; Wang, W.D.; Song, Y.T.; Cao, Y.B. Oil-Water Interfacial Activities of RhamnolipidSophorolipid Mixed Biosurfactants Systems and Their Effects on Oil Displacement Efficiency. Period. Ocean. Univ. China 2015, 45, 72-77. [CrossRef]

46. Ke, C.Y.; Sun, W.J.; Li, Y.B.; Hui, J.; Lu, G.M.; Zheng, X.; Zhang, Q.Z.; Zhang, X.L. Polymer-Assisted Microbial Enhanced Oil Recovery. Energy Fuels 2018, 32, 5885-5892. [CrossRef] 